\title{
Inscribir, mostrar y recrear una cicatriz: infancia y escritura en la novela autobiográfica del Caribe
}

\section{To inscribe, to Show and to Recreate a Scar: Children and Writing in the Autobiographical Novel of the Caribbean}

\author{
Claudia Amigo \\ Universidad de São Paulo \\ camigopino@gmail.com
}

\section{Resumen:}

¿Qué papel tiene la escritura en un relato de infancia? El presente artículo intenta responder esa pregunta a partir de la lectura de tres narrativas de inspiración autobiográfica del Caribe: Chemin décole [Camino a la escuela] (1994), de Patrick Chamoiseau; Una casa para Mr. Biswas, de V.S. Naipaul (1961) y Le coeur à rire et à pleurer [Un corazón que ríe y llora] (1999), de Maryse Condé. En todas esas obras observamos los momentos en que la escritura se torna un problema para los personajes-niños y relacionamos esos episodios con la imagen de la cicatriz. Hacia el final, esbozamos una relación posible entre esa imagen y el concepto de glocalización, de Zygmunt Bauman.

Palabras clave: infancia, escritura, Patrick Chamoiseau, Maryse Condé, V.S. Naipaul.

\begin{abstract}
:
What is the role of writing in the narrative of childhood? This article attempts to answer that question by reading three autobiographical narratives of the Caribbean: Chemin d'école [Road to school] (1994), by Patrick Chamoiseau, A House for Mr. Biswas, by V.S. Naipaul (1961) and Le coeur à rire et à pleurer [A heart that laughs and weeps] (1999), by Maryse Condé. In all these works, we observed the moments in which writing becomes a problem for the children characters and we relate these episodes to the image of the scar. Towards the end, we outline a possible relation between this image and the concept of glocalization, proposed by Zygmunt Bauman.
\end{abstract}

Keywords: Childhood, Writing, Patrick Chamoiseau, Maryse Condé, V.S. Naipaul. 


\section{El poder incómodo de la escritura}

La escritura ha sido un concepto importante para la teoría francesa de finales de siglo XX. En 1953, Roland Barthes lo coloca en el centro de la reflexión de su primer libro, El grado cero de la escritura. En vez de hacer referencia al acto físico de escribir, para Barthes la escritura está relacionada con la postura del escritor en relación con la tradición literaria en la cual está inserto. Su propuesta es radical: plantea la sustitución de la palabra literatura por la palabra escritura: la literatura estaría definida por la tradición, mientras que la escritura es siempre una negatividad hacia la tradición. La literatura tendría géneros, influencias, seguidores; la escritura no. Cualquier género, incluso la crítica literaria, podría definirse como escritura en tanto inscribiera una diferencia respecto de la literatura. Así, en la década de 1950, Barthes inaugura la visión de la producción literaria ya no como un producto, sino más bien como un movimiento de contestación (Barthes 179).

Así, la escritura toma el lugar de la literatura. En la década siguiente, el concepto ganará aun más amplitud: para Barthes, la escritura no es solo una nueva forma de referirse a la literatura, sino también una nueva forma de concebir la memoria. Con base en los primeros escritos de Freud, Derrida afirma que la memoria funciona como una escritura, es decir, como establecimiento de una diferencia entre las marcas dejadas por la percepción en nuestro organismo. De la misma manera que escribir es trazar diferencias gráficas en un papel, recordar entonces es establecer las diferencias entre las rupturas -las cicatrices- en nuestro cuerpo (Derrida).

La escritura se había tornado no solo un concepto, sino la base constituyente del sujeto. La visión de Lacan sobre el sujeto, que en mucho dialoga con Derrida, lo muestra como una escritura sin fin, que pasa de un significante a otro significante. Junto a esa valorización conceptual del término escritura, también se observó en Francia una valorización del propio acto de escribir. Mientras Derrida y Lacan trazaban su teoría del sujeto, la Biblioteca Nacional de Francia compraba manuscritos y trataba de estimular la investigación de sus archivos. En medio de las barricadas de 1968, un grupo de investigadores de los manuscritos de Heinrich Heine decide proponer una nueva disciplina, que estudiaría la génesis de las obras literarias, a partir de los documentos dejados por los escritores. Esa disciplina, llamada crítica genética, fue poco a poco ocupando su lugar dentro de los estudios literarios franceses y hace treinta años tiene un laboratorio del CNRS (Centro Nacional de la Investigación Científica), dedicado a entender cómo escriben los escritores, qué hacen con sus manuscritos, cómo desechan lo que no van a usar, cuáles son los diferentes tipos de escritura, en qué se diferencian la escritura musical, la escritura literaria, la escritura científica y cuáles son los soportes actuales de la creación, ahora que ya pocos escriben a mano (Amigo y Zular).

En ese contexto, es notable la poca atención que ha tenido una de las más ricas expresiones de la literatura francesa: la escritura del Caribe. La primera publicación dedicada a ella surgió apenas en 2012, con el lanzamiento de la revista Génesis, dedicada al tema "África-Caribe". Todavía con muy pocas reproducciones de documentos, notamos en esa publicación una falta de discusión relativa a la incomodidad que produce la pala- 
bra escritura dentro del contexto caribeño. Han habido escasas manifestaciones sobre el proceso de creación de los escritores del Caribe, tal vez porque el concepto de escritura tiene repercusiones muy particulares en la región.

\section{Escrituras del Caribe}

Es posible observar ese lugar diferente de la escritura tanto en los pensadores como en los escritores caribeños. Por ejemplo, en una entrevista realizada a la escritora guadalupana Maryse Condé (1937), con el propósito de interrogarla sobre sus manuscritos, sus cuadernos y sus anotaciones, ella negó conservar cualquier rastro de sí misma, de su escritura y de su memoria:

Nunca utilizo documentos escritos antes. Todo surge de la memoria, de la imaginación, mezcla de recuerdos verdaderos y falsos. Porque para el escritor no importa si él imagina o recuerda. Perdí todos mis álbumes de fotos en Senegal. No tengo ni siquiera una imagen de mi madre, muerta cuando era adolescente, ni mía, cuando niña. Para escribir no las necesito. Yo las recreo (cit. en Amigo 30) ${ }^{1}$.

En relación con los pensadores de la literatura, destaco las afirmaciones de Édouard Glissant, por ejemplo, que señala que la resistencia a la escritura está dada por la irrigación de la escritura a través de la oralidad. Como en el Caribe francés los niños hablan créole en casa, pero tienen que escribir en francés en la escuela, la escritura no se considera una construcción, sino la marca de una tensión (Glissant 554).

También según Glissant, la negación de los rastros a la que alude Condé está relacionada con una cierta visión de la historia propia de los pueblos del Caribe. Los habitantes "nativos" de las islas, los indios caraibas, fueron exterminados por el colonizador; los esclavos fueron arrancados de sus tierras, de su cultura, obligados a trabajar sin poder guardar ningún rastro de lo que fueron y, luego, al incorporarse a la sociedad francesa, también tuvieron que borrar su pasado de esclavos y el único idioma que conocían (el créole). La reconstrucción de un pasado en esas condiciones se tornaba forzada porque su cronología está constituida de apagamientos y contradicciones. Por eso, afirma Glissant, los pueblos del Caribe habrían hecho una "economía de la génesis":

Comprendemos que los pueblos "manifiestamente" compuestos hayan hecho la economía de una génesis. El "fin" de cualquier génesis es el comienzo de esa filiación por la cual nos persuadimos de la unicidad preservada. Los pueblos compuestos, es decir, los que no sabrían negar ni disimular su composición, ni sublimarla en el Uno imaginario, no

1 Je n’utilise jamais aucun document écrit à l’avance. Tout est surgissement de la mémoire, imagination, mélange de souvenirs vrais et faux. Car pour lécrivain, qu'importe qu'il imagine ou se souvienne. J'ai perdu mes albums de photos au Sénégal. Je n’ai même plus une image de ma mère, morte quand jétais enfant, ni de moi, petite fille. Pour écrire, je n’ai pas besoin. Je les recré. 


\begin{abstract}
"necesitan" una génesis, porque no necesitan una filiación. Los únicos rastros de una "génesis" que se vislumbran en el cuento antillano son satíricos y burlescos. Dios sacó muy rápido del horno de la creación el Blanco (crudo), muy tarde al Negro (quemado); lo que llevaría a pensar en esa versión que el Mulato -con el que el antillano quisiera confundirse- es el único que fue cocido a punto. Pero otra versión de esas tres horneadas dice que la primera de hecho estaba demasiado cruda, la segunda no suficientemente cocida (los Mulatos) y la tercera, a punto (los negros). La conciencia martinicana siempre está atormentada de posibles contradictorios. (Esas parodias de génesis no pretenden en todo caso dar una explicación de los orígenes; ellas suponen la sátira de cualquier génesis transcendental producida.) La poética del mestizaje es la misma de la Relación: no lineal y no profética, tejida de ardientes paciencias, de derivadas incomprensibles (Glissant 430)2.
\end{abstract}

De esa manera, discutir acerca de la escritura en el Caribe implica tratar de entender una nueva lógica de creación, tal vez no compuesta de rastros, sino de marcas de apagamientos sucesivos. Para eso, aquí proponemos acercarnos a los relatos sobre la escritura. En pocos casos observamos relatos sobre personajes escritores, o personajes que se debaten con la escritura: lo que sí encontramos son varios relatos de niños que se debaten con el aprender a escribir. En esta primera aproximación al tema, planteamos la observación de tres narrativas de infancia de inspiración autobiográfica que narran la experiencia del embate de la escritura: Chemin décole (Camino a la escuela) (1994), de Patrick Chamoiseau; Una casa para Mr. Biswas, de V.S. Naipaul (1961) y Le coeur à rire et à pleurer (Un corazón que ríe y llora) (1999), de Maryse Condé.

\title{
La escritura como cicatriz
}

\section{Chamoiseau: aprender a escribir es aprender a herirse}

Después de la muerte de Édouard Glissant, Patrick Chamoiseau (1953) es probablemente el escritor más importante de la Martinica, y es conocido no solo por su trabajo como novelista, sino también por ser defensor del uso de la lengua créole. Junto a los escritores

2 On comprend que des peuples 'manifestement' composites aient fait l'économie d'une Genèse. C'est que la 'fin' de toute Genèse est le début de cette filiation par où on se persuade de l'unicité préservée. Des peuples composites, c'est-à-dire qui ne sauraient nier ni déguiser leur composition, ni la sublimer dans l'Un imaginaire, nont pas 'besoin' d'une Genèse, parce qu'ils n’ont pas besoin d'une filiation. (Les seules traces de 'genèse' qu'on repère dans le conte antillais sont satiriques et ricanantes. Dieu a enlevé trop vite du four de la Création le Blanc (blême), trop tard le Nègre (brûlé); ce qui tendrait à laisser croire dans cette version que le Mulâtre - avec lequel l'Antillais voudrait donc se confondre - est le seul à avoir été cuit à point. Mais une autre version de ces trois fournées dit que la première était en effet trop blême, la deuxième pas assez cuite (les Mulâtres) et la troisième à point (les Nègres). La conscience martiniquaise est toujours tourmentée de possibles contradictoires. (Ces parodies de genèse ne prétendent en tout cas pas donner une explication des origines; elles supposent la satire de toute Genèse transcendantale donnée.) La poétique du métissage est celle même de la Relation: non linéaire et non prophétique, tissée d’ardues patiences, de dérivées incompressibles. 
Raphael Confiant y Jean Bernabé, publicó en 1989 el Éloge de la créolité, manifiesto que destaca el créole como la matriz de la identidad del caribe francés, e incentivó el uso y el estudio de esa lengua en escuelas y universidades (Bernabé, Chamoiseau y Confiant).

Un año después de publicar el Éloge, Chamoiseau empezó a escribir una autobiografía de su infancia en tres partes, a la que llamó Une enfance créole (Una infancia créole). El primer libro se publicó en 1990 con el nombre Antan d'enfance (Antaño de infancia), el segundo en 1994, con el nombre Chemin décole (Camino a la escuela), y el tercero en 2005, À bout d'enfance (Final de infancia). Aquí nos interesa especialmente el segundo libro, en que el autor se concentra exactamente en los primeros años de escuela y en el aprendizaje de la escritura en francés.

El personaje principal, que sería el propio Chamoiseau, se llama négrillon, o negrito, y todo lo que quiere en el inicio del libro es hacer lo que hacen sus hermanos: ir a la escuela. Su mamá lo lleva y él se divierte, pero ese era apenas el jardín infantil. Cuando empieza a frecuentar la verdadera escuela, se da cuenta de que está lejos de ser un juego de niños y comienza a descubrir un sufrimiento que antes ignoraba. Lo que exigía el maestro de la escuela preparatoria no era disciplina, no era repetición, no era conocer cosas nuevas, como en el jardín. El maestro exigía expresarse en un idioma que él nunca había usado para hablar de sí mismo:

Mamita, qué fierro [...] El negrito, confundido, se dio cuenta de que no sabía esa lengua. La voz parlante chiquitita de su cabeza manejaba otra lengua, su lengua-casa, su lengua mamita, su lengua no aprendida, pero integrada sin restricciones al filo de sus deseos del mundo. Un francés extranjero surgía en rasgos fugaces y esporádicos; él los había oído en alguna parte, y los repitió en circunstancias mal identificadas. Otro francés más cercano, aclimatado pero también muy reducido, se encontraba también en los bordes de las intensidades de su cabeza. Pero hablar en realidad para decir, dejar salir una emoción, un sentimiento, dejarse llevar, expresarse mucho tiempo, exigía su lengua-mamita que, ayayay, en el espacio de la escuela se tornaba inútil.

Y peligrosa.

¡Oh, qué fierro! [...] (Chamoiseau 66)

El pasaje citado se abre y se cierra con la misma alusión a un "fierro". La palabra fierro en ese contexto puede aludir a las cadenas de los esclavos e incluso al fierro usado para marcarlos. Pero en cualquiera de las alternativas, la referencia es evidente: es el castigo a los esclavos, que el negrito empieza a conocer al mismo tiempo que aprende la existencia

3 Manman, quel fer [...] Le négrillon, dérouté, comprit qu'il ignorait cette langue. La petite-voix babilleuse de sa tête maniait une autre langue, sa langue-maison, sa langue manman, sa langue-non-apprise intégrée sans contraintes au fil de ses désirs du monde. Un français étranger y surgissait en traits fugaces et rares; il les avait entendus quelque part et il les répétait lors de circonstances mal identifiées. Un autre français plus proche, acclimaté mais tout aussi réduit, se tenait en lisière des intensités vivantes de sa tête. Mais parler vraiment pour dire, lâcher une émotion, balancer un senti, se confier à soi-même, s'exprimer longtemps, exigeait cette langue-manman qui, ayayaye, dans l’espace de lécole devenait inutile. / Et dangereuse./ Ô quel fer ! [...] 
de ese francés completamente extranjero, que no servía para expresar ningún sentimiento. Las palabras en cursiva usadas en ese pasaje nos permiten pensar que tal vez se trate de otra instancia narrativa, de otro narrador, o tal vez de otro tiempo. Aunque no sepamos exactamente quién habla ahí, sabemos que hay una conexión con el mundo de la esclavitud, que no existe más entre los años 1950 y 1960, cuando, supuestamente, ocurre el relato de infancia del libro. Otra alusión al castigo físico está dado por el desprendimiento de su cuerpo: quien habla no es más él, sino "la voz parlante chiquitita de su cabeza". El que debe hablar francés no es el mismo que habla en la lengua "mamita" (el créole): observamos un corte en el cuerpo, que se repetirá en otros momentos de la narrativa.

Buena parte del trabajo del maestro consistía en enseñar a hablar francés: la pronunciación correcta, el vocabulario adecuado. Los niños se equivocaban, pronunciaban las vocales del créole, omitían el fonema /r/, y cuando finalmente lograban usar las palabras francesas, lo hacían para componer imágenes y expresiones extrañas, propias del créole. Por más que los reprimiera, el créole siempre salía por alguna parte. Su reacción era violenta:

Entonces el maestro castigaba brutalmente, se burlaba, ridiculizaba, regañaba, lloraba, gritaba, hacía muecas, movía un pie. Apretaba a uno, pellizcaba a otro, tratando de avisar al que hablaba mostrando sus propios labios articulando o le imponía un silencio brutal a otro que había empezado "mal". A veces toda la clase servía de testigo: ¿Has escuchado a este animal?, para que un pequeño retornado-de-Francia se levantara triunfalmente y mostrara un correcto modelo del buen acento (Chamoiseau 82) ${ }^{4}$.

Como en el pasaje anterior, observamos el acercamiento al espacio-tiempo de la esclavitud: el maestro toma el lugar del capataz de esclavos, que trata a los niños literalmente de animales y se transforma él también en animal (al gritar, hacer muecas, deformarse). Aprender a hablar bien en francés, primer paso para aprender a escribir, es incorporar, de forma inconsciente, el mismo castigo de la esclavitud que significa la violencia física, pero también la humillación frente a los demás, la demostración de la superioridad (y la humanidad) del extranjero. Como en el otro pasaje, vemos aquí que el castigo del maestro ocurre al mismo tiempo en que se apaga su cultura y la de su familia, su "lengua-mamita".

Como se trata de una autobiografía asumida por el autor, el lector sabe que el negrito del libro se transformó en escritor. Hizo de aquello que lo humillaba, de aquello que lo hería, de aquello que lo reducía, una forma de sobrevivir. ¿Por qué? Tal vez la respuesta se encuentre en la frase final del libro: "El negrito, apoyado sobre su cuaderno, inscribía una marca de sobrevivencia” (Chamoiseau 189). A pesar de que la escritura es apagamiento de la cultura oral-familiar, es también una forma de acercarse al pasado, a los que sobrevivieron negándose, humillándose. Y así, lo que era en principio un apagamiento

4 Alors le Maître sévissait, se moquait, raillait, grondait, pleurait, hurlait, grimaçait, secouait un pied. Il serrait à gauche, purgeait à droite, tentait de prévenir en montrant ses propres lèvres en train d’articuler à celui qui parlait ou imposait un silence brutal à tel autre qui avait "mal" démarré. Parfois, il prenait à témoin l’ensemble de la classe, Avez-vous entendu cet animal ?, en sorte qu'un petit-revenu-de-France se lève triomphant et assène la juste règle du bon accent. 
como el apagamiento original producido por la esclavitud, se transforma en una especie de memoria de aquellos que sobrevivieron. Escribir en ese idioma extranjero es recordar en todo momento el pasado, la esclavitud, el hecho de que el negrito no es de ninguna forma un francés, a pesar de los esfuerzos del maestro por convencerlo de lo contrario.

\section{Naipaul: mostrar la cicatriz}

V. S. Naipaul (1932) es tal vez uno de los autores más célebres de todo el Caribe. Su historia difiere bastante de la de Chamoiseau; de origen hindú, Naipaul nació en Trinidad y Tobago (donde la población es mayoritariamente de origen hindú) y vivió prácticamente toda su vida en Inglaterra. En 2001 ganó el Premio Nobel de Literatura. Una casa para Mr. Biswas, el libro que exploraremos aquí, es una de sus primeras novelas. A pesar de que no propone en ningún momento un pacto autobiográfico, el autor reconoció en diversas ocasiones que la historia de ese libro estaba inspirada en su padre. Así, Anand, el único hijo del Mr. Biswas en el libro, quien gana una beca y se va a estudiar a Inglaterra muy joven, puede homologarse al negrito de Chamoiseau: un niño que en el futuro se tornará escritor.

En la novela, Naipaul no describe el momento en que aprende a escribir ni el conflicto inicial entre el hindi (el idioma hablado dentro del ambiente familiar) y el inglés, pero sí los diálogos entre los niños al exterior de la escuela. Mientras en el relato de Chamoiseau el maestro debe imponer el uso del francés, en la novela de Naipaul son los niños los que controlan el uso del inglés y se ríen y humillan a aquellos que usan el hindi:

Y algunos días después, cuando surgió un nuevo juego en la escuela - ¿cómo llamaban los niños a sus padres?- Anand, apenas para humillarse, mintió, diciendo que los llamaba bap y mai, y fue ridiculizado por todos. Vidiadhar, sin embargo, que ya había pasado por la escuela, a pesar del poco tiempo que estaba en ella, respondió sin vacilar que los llamaba "Mummy and Daddy." Porque esos niños que llamaban a sus padres de ma y $p a$, todos originarios de hogares donde la súbita torrente de dólares americanos desencadenara la ambición, la agresividad y la incerteza, esos niños estaban empezando a tomarse demasiado en serio el ramo de redacción en inglés: sus Daddies trabajaban en oficinas, y en los fines de semana Daddy y Mummy los llevaban en auto a la playa, con pesados canastos de comida (Naipaul 338$)^{5}$.

Mientras los niños de Chamoiseau percibían y sufrían con la imposición de un francés artificial, que no estaba presente en sus vidas domésticas, los niños de Naipaul "se

5 And a few days later, when a new quiz was going round the school - what did the boys call their parents? - Anand, wishing only to debase himself, lied and said, "Bap and Mai", and was duly derided; while Vidiadhar, shrewd despite his short stay at the school, unhesitatingly said, "Mummy and Daddy.. For these boys, who called their parents $\mathrm{Ma}$ and $\mathrm{Pa}$, who all came from homes where the sudden flow of American dollars had unleashed ambition, push and uncertainty, these boys had begun to take their English compositions very seriously: their Daddies worked in offices, and at week-ends Daddy and Mummy took in cars to the seaside, with laden hampers. 
tomaban demasiado en serio el ramo de redacción”, es decir, transformaban esa redacción artificial en lo que creían vivir. Ellos ciertamente no tenían daddies que trabajaran en oficinas, pero así lo hacían creer: su redacción se había transformado en su vida. De esa forma apagaban la cicatriz, la marca de la diferencia y por lo tanto la memoria de un pasado de apagamientos. Anand toma un extraño partido en este pasaje: él escoge mostrar la cicatriz, que él mismo, en su casa, había apagado, ya que todos hablaban inglés en el ambiente familiar. ¿Por qué tomar esa actitud? ¿Por qué escoger ser humillado? Porque es una forma de mostrar respeto hacia una clase en ascenso, mientras su padre y su familia continúan en el mismo estado de pobreza. Así, la cicatriz es la memoria de un pasado, pero también la memoria de una condición social actual, de una humillación colectiva que sigue existiendo.

\section{Condé: recrear la cicatriz}

Nacida en Guadalupe, Maryse Condé (1937) es una figura aparte en el ambiente del caribe francés. No participa de movimientos, no firma manifiestos y vivió buena parte de su vida en Estados Unidos. Al contrario de la mayoría de los escritores caribeños, no relata en su autobiografía conflictos lingüísticos entre el ambiente escolar y el ambiente doméstico. Como sus padres escondían a sus hijos todas las implicaciones del origen esclavo, no permitían que se hablara créole en casa, y Maryse apenas lo conocía por el contacto con las empleadas domésticas.

El conflicto con la escritura se produce cuando Condé pasa un periodo en Francia junto a su familia y una profesora de francés, comunista, le pide una última tarea ${ }^{6}$ : "Maryse, háganos una presentación sobre un libro de su país". El objetivo de la profesora, según la narradora, es desahogarla sobre el peso que tiene en su corazón (la ignorancia de los franceses de su condición, del sufrimiento de su pueblo). Sin embargo, esa propuesta bien intencionada la hace sumergirse en un abismo de confusión (Condé 115).

A pesar de ser casi adolescente, no conoce ningún libro de un escritor de Guadalupe. Hasta ese momento, ha creído que los escritores de su país eran Flaubert, Zolá, Proust. Tiene que preguntarle a su hermano mayor, Sandino, también comunista, que le indique un título. Finalmente, decide centrar su presentación en un libro llamado La rue Cases Negres, de Joseph Zobel, que cuenta la infancia de un niño que trabaja en las plantaciones de caña de azúcar. Reconoce que un abismo los separaba a ella y a José, el protagonista: ella venía de una familia rica, nunca tuvo que ocupar la posición del esclavo y poco conocía de esa cultura. Pero, para los otros, ella tenía que ocupar ese lugar, ella tenía que tener el vientre hinchado por las lombrices, las piernas arqueadas, el pelo quemado, tenía que no saber bien el francés: ella tenía que ser una Josefita.

6 Es curioso que ese capítulo en el libro de Condé tiene el mismo título que el libro de Chamoiseau: "Chemin d'école" (Camino a la escuela). 
Lo que su familia se ha esforzado en ocultar durante su infancia, la cicatriz que ella no ve, los niños franceses y la profesora sí la ven: está en el color de su piel. En ese momento, tiene que empezar a construir el conflicto que sus padres han borrado, lo que en un principio llama su "compromiso político":

Hoy en día, me inclino a creer que lo que más tarde llamé, pomposamente, "mi compromiso político" nació a partir de ese momento, de mi identificación forzada con el desafortunado José. La lectura de Joseph Zobel, más que los discursos teóricos, me abrió los ojos. Entonces me di cuenta de que el medio al que pertenecía no tenía absolutamente nada que ofrecer y yo empecé a tomarle distancia. Gracias a él, yo era sin sabor ni aroma, una mala calcomanía de los pequeños franceses que me rodeaban. Yo era "piel negra, máscara blanca” y es para mí que Frantz Fanon iba a escribir (Condé 119-20)

La tarea de infancia le permite a Maryse Condé entender que no hay forma de ignorar la herida social de la esclavitud y la imposición señorial del francés. La cicatriz que los niños de Chamoiseau o Naipaul perciben al aprender a hablar y escribir el francés, Maryse Condé lo advierte en el momento de crear un texto, o de crearse a sí misma. Su reacción no será negar a los franceses, sino negar a la propia Guadalupe, a su familia, a su creación alienada, de la que huyó durante muchos años y de la que no guardó, como vimos, ningún documento. El apagamiento del que hablaba en la entrevista que citamos en el comienzo de este texto no era de ninguna forma un apagamiento del pasado esclavo, sino de su pasado burgués del Caribe, el pasado construido por sus padres, que inconscientemente la obligaban a no ver la herida que todos veían en el color de su piel.

\section{La escritura de la glocalización}

En circunstancias y momentos muy distintos, los niños de Chamoiseau, Naipaul y Condé describen la escuela como el lugar de ruptura que les permite reconocer en su presente la herencia de un pasado de esclavitud. Pero en los tres casos estuvimos lejos de encontrar en la escuela la descripción, por parte de los profesores, de la estructura o de la historia colonial. Es en el aprendizaje de la lengua y en el dominio de la escritura que se encontrarán los focos de conflicto descritos en los textos autobiográficos que aquí analizamos.

Para finalizar, haremos una breve relación entre el papel del aprendizaje de la escritura en el Caribe y las ideas del sociólogo Zygmunt Bauman sobre el proceso de glo-

7 Aujourd'hui, tout me porte à croire que ce que j’ai appelé plus tard un peu pompeusement "mon engagement politique" est né de ce moment-là, de mon identification forcée au malheureux José. La lecture de Joseph Zobel, plus des discours théoriques, m’a ouvert les yeux. Alors j’ai compris que le milieu auquel j’appartenais navait rien de rien à offrir et j’ai commencé de le prendre en grippe. À cause de lui, jétais sans saveur ni parfum, un mauvais décalque des petits Français que je côtoyais.

J’étais "peau noire, masque blanc" et c’est pour moi que Frantz Fanon allait écrire. 
calización. Bauman sostiene que en el mundo globalizado el deseo de riqueza siempre se acompaña del deseo de movilidad. Así, si una empresa tiene una sede en una localidad en que los trabajadores producen algún conflicto, la empresa, para seguir enriqueciéndose, debe moverse e irse a otro lugar (y, por supuesto, olvidar los conflictos de la localidad original). El enriquecimiento globalizado lleva al empobrecimiento cada vez mayor de la localidad, en lo que Bauman llama proceso de glocalización:

La mentira de la promesa del libre comercio es bien encubierta; la conexión entre la creciente miseria y desesperación de los muchos "inmovilizados" y las nuevas libertades de los pocos con movilidad es difícil de percibir en los informes sobre las regiones lanzadas en la punta sufridora de la "glocalización". Parece, al contrario, que los dos fenómenos pertenecen a mundos muy diferentes, cada uno con sus propias causas marcadamente diversas. Jamás se sospecharía por los informes que el rápido enriquecimiento y el rápido empobrecimiento brotan de la misma raíz, que la "inmovilidad" de los miserables es un resultado tan legítimo de las presiones "glocalizantes" como las nuevas libertades de los bien afortunados para los que el cielo es el límite [...] (Bauman 80).

Tenemos la impresión de vivir en un mundo donde "las riquezas son globales, la miseria es local", pero en verdad se trata del mismo fenómeno. Con la posibilidad constante de movilidad del capital, con el objetivo de acumular más y más riquezas, la localidad es abandonada y muchas veces escondida. Un indicio de localidad se transforma, así, en un indicio de miseria.

La enseñanza de la escuela caribeña descrita en los relatos de Chamoiseau, Naipaul y Condé tiene claramente el objetivo de huir de la localidad e insertar a los niños en un mundo donde la movilidad es posible. De hecho, los niños de Naipaul y Maryse Condé viajarán al final de los relatos para estudiar en la metrópolis, lo que es en general el destino de los mejores alumnos de las escuelas del Caribe. En el caso del caribe francés, por lo menos, un exitoso currículo escolar tiene como premio la movilidad y un futuro de funcionario en Europa o en alguna otra excolonia. Pero para llegar a ese objetivo es necesario negar esa localidad dolida que no permitiría abrazar sin conflictos la riqueza segura de la vida en la metrópolis. Así, aprender a hablar, a trazar, a escribir y a componerse a sí mismo debe consistir sobre todo en olvidar su idioma, su cultura, su pasado o su "sabor", como afirma Condé.

Pero aquí observamos el caso inverso: mientras atentaba contra la localidad, la escuela los hacía percibir la cicatriz que los constituía y que los obligaba a tomar una posición de distancia hacia la globalización, descrita por Condé como su "compromiso político". La escritura, la marca de sobrevivencia, más que aprendizaje de la globalización, se transforma en la conciencia del proceso de glocalización. Las consecuencias de esa conciencia son distintas en cada uno de los escritores que vimos aquí. En el caso de Maryse Condé observamos muchos relatos de migración, en que los personajes parten en busca de una situación mejor pero vuelven tanto o más pobres que antes. Pero tal vez 
la consecuencia más clara en los tres escritores sea la irrigación de la lengua escrita por la lengua oral ya sea en forma de introducción de palabras de los idiomas usados en el convivio oral (créole o hindi), ya sea por las estructuras de las frases o por las imágenes usadas. Esa es la lucha posible contra la escritura: nada más que una ilusión, como dice Édouard Glissant, pero que tiene la ventaja de no ocultar y de dejar siempre visible la cicatriz que los constituye:

Otra resolución: la oposición jerarquizada entre lengua hablada y lengua escrita no tiene aquí -para mí- más sentido; porque la lengua créole que me es natural viene a todo momento a irrigar mi práctica de la escritura del francés, y mi lengua proviene de esa simbiosis, tal vez extranjera a las artimañas de la mezcla, pero querida y dirigida por mí. Y, si sucumbo aquí a una ilusión, por lo menos puedo esperar que otros la reconocerán y así le darán continuidad. Porque si la alienación aumenta en esa materia, solo el acto de los pueblos puede denunciarla. Se trata entre otros de deshacer la escritura de su mandato de soberanía en relación a la oralidad (Glissant 554$)^{8}$.

Volviendo a nuestra discusión inicial, mientras la escritura empieza a ocupar un lugar de soberanía en el ambiente intelectual francés, en la literatura del Caribe tiene que perder la soberanía. En todo caso, se trata de soberanías diferentes: mientras para Barthes o Derrida la escritura es una forma de conocimiento que busca una soberanía en relación con el conocimiento por clasificación, para Glissant la escritura debe perder su soberanía en relación con la lengua oral. Y para eso, propone una escritura de la lengua oral en la lengua escrita. El créole se inscribe en el francés en los textos literarios y construye, en sentido contrario, las mismas cicatrices que se formaron en el aprendizaje de la escritura en la infancia.

En la narrativa de Chamoiseau, cuando los niños finalmente logran pronunciar bien el francés, lo hacen de una forma extraña, usando las imágenes y los dichos del créole. En la novela de Naipaul, un niño que asimilaba muy bien el inglés decide exponer un uso de la lengua hindi que él ya no hace: es su forma de mostrar su condición social. En el relato de Condé, el extrañamiento producido al leer la literatura del Caribe la lleva a percibir su propia alienación. En el sentido contrario, la narrativa francesa de Chamoiseau será también un texto extraño, irrigado de imágenes del créole. La novela de Naipaul es una exposición descarnada de la pobreza y de la imposibilidad de realizar el sueño más común de la sociedad burguesa: tener una casa. Y el relato de Condé termina con la decisión de apagar su pasado alienado, así como sus padres y la escuela del Caribe habían apagado su pasado esclavo. La localidad, antes reprimida, "glocalizada", se vuelve contra la globalidad: se inscribe en ella, produce cicatrices.

8 Autre "résolution": l’opposition hiérarchisée entre langage parlé et langue écrite n’a pas ici -pour moi- plus de sens ; car la langue créole qui m’est naturelle vient à tout moment irriguer ma pratique écrite du français, et mon langage provient de cette symbiose, sans doute étrangère aux ruses du panachage, mais voulue et dirigée par moi. Et, si je succombe ici à une illusion, du moins puis-je espérer que d’autres l'accuseront et continueront plus outre. Car, si l'aliénation grandit en cette matière, seul l'acte des peuples peut le dénoncer. Il s’agira entre autres de défaire lécriture de son mandat de souveraineté par rapport à l'oralité. 
De esa forma, los dos movimientos no son tan opuestos como parecen. La lucha contra la soberanía de la escritura se produce también en forma de escritura.

\section{Referencias}

Amigo, Claudia. "Écrire pour éffacer, éffacer pour écrire". Écritures du XXIeme siècle. París: Le manuscrit, 2012. 19-33. Medio impreso.

Amigo, Claudia y Roberto Zular. Escrever sobre escrever. Uma introdução crítica à crítica genética. San Pablo: WMF Martins Fontes, 2007. Medio impreso.

Barthes, Roland. Oeuvres Complètes. Vol. I. París: Seuil, 2002. Medio impreso.

Bauman, Zygmunt. Globalização. As consequências humanas. Río de Janeiro: Jorge Zahar, 1999. Medio impreso.

Bernabé, Jean, Patrick Chamoiseau y Raphaël Confiant. Éloge de la créolité. París: Gallimard, 1993. Medio impreso.

Chamoiseau, Patrick. Chemin d'école. Une enfance créole II. París: Gallimard, 1994. Medio impreso.

Condé, Maryse. Le coeur à rire et à pleurer. París: Robert Laffont, 1999. Medio impreso. Medio impreso.

Derrida, Jacques. A escritura e a diferença. San Pablo: Perspectiva, 1971. Medio impreso.

Glissant, Édouard. Le discours antillais. París: Gallimard, 1981. Medio impreso.

Naipaul, V.S. A house for Mr. Biswas. Nueva York: Vintage, 2001. Medio impreso. 